\title{
Preparation of Phospholipid Polymers and Their Properties as Polymer Hydrogel Membranes
}

\author{
Kazuhiko IshIHARA, Tomoko Ueda, and Nobuo NaKabaYashi \\ Institute for Medical and Dental Engineering, \\ Tokyo Medical and Dental University, \\ 2-3-10, Kanda-Surugadai, Chiyoda-ku, Tokyo 101, Japan
}

(Received October 9, 1989)

\begin{abstract}
A methacrylate monomer having the phospholipid polar group, 2-methacryloyloxyethyl phosphorylcholine (MPC) was prepared by an improved method with good yield. MPC was copolymerized with $n$-butyl methacrylate (BMA). The polymer membranes were prepared from the poly(MPC-co-BMA) by a solution casting method. The membrane adsorbed water well and became a hydrogel structure even MPC mole fraction in the copolymer was 0.04 . The water content of the hydrogel membrane increased with increase of MPC units and rise of temperature. These properties of the hydrogel membrane were attributed to the highly hydrophilic phospholipid polar group in the copolymer. Water soluble organic compounds and proteins whose molecular weights were below $10^{4}$ permeated through the hydrogel membrane. However, the protein could not permeate when the molecular weight was higher than $10^{5}$.

KEY WORDS Phospholipid Polymer / 2-Methacryloyloxyethyl Phosphorylcholine / Membrane/ Hydrogel / Water Content / Temperature Response / Permeation / Biomaterials
\end{abstract}

Phospholipids are the main components of the biomembrane and interesting substances in biological and biomedical field. ${ }^{1,2}$ Recently, the phospholipid membrane has been used as a drug carrier, sensor, separation membrane. ${ }^{3}$ However, these phospholipid membranes were unstable physically and chemically, because the phospholipids constituting membranes do not bond covalently and have high mobility. To improve the mechanical strength of the phospholipid membranes, phospholipid molecules with polymerizable group were synthesized. $^{4,5}$

We have developed new biocompatible materials based on the results that the surface of polymeric material showing good biocompatibility was covered with phospholipid molecules and formed biomembrane-like structure on the material. Therefore, a methacrylate having phosphorylcholine moiety, 2-methacryloyloxyethyl phosphorylcholine
(MPC) was synthesized and its copolymerization ability with methyl methacrylate was evaluated. ${ }^{6}$ Moreover, the blood compatibility of the poly(MPC-co-MMA)s has been investigated. $^{7}$

Since MPC is an extremely hydrophilic monomer, MPC copolymers with hydrophobic monomer are hydrogels. The hydrogels are expected to useful biomaterials. ${ }^{8}$ In this article, improvement of the preparation method of MPC and basic properties of MPC copolymers with $n$-butyl methacrylate as a hydrogel is described.

\section{EXPERIMENTAL}

\section{Materials}

2-Chloro-2-oxo-1,3,2-dioxaphospholane (COP) was synthesized according to the method of Edmundson and purified by distillation under reduced pressure, bp $98^{\circ} \mathrm{C} /$ 
$1 \mathrm{mmHg}$ (lit.: bp $79^{\circ} \mathrm{C} / 0.4 \mathrm{mmHg}$ ) ${ }^{9}$ 2-Hydroxyethyl methacrylate (HEMA) and $n$-butyl methacrylate (BMA) were distilled under reduced pressure of argon, and fractions of $b p$ $65^{\circ} \mathrm{C} / 3 \mathrm{mmHg}$ and $60^{\circ} \mathrm{C} / 30 \mathrm{mmHg}$ were used, respectively. 2,2'-Azoisobutyronitrile (AIBN) was recrystallized from methanol. Tetrahydrofuran (THF), acetonitrile, and triethylamine (TEA) were purified by conventional way. Acrylamide (AAm) was recrystallized from benzene. Extra pure grade 2-acrylamide2-methyl propane sulfonic acid (AMPS) was kindly gifted from Nitto Chemical Co., Ltd. Poly(HEMA) was synthesized by a homopolymerization of HEMA in 2-propanol using AIBN as an initiator. Bovine serum albumin, bovine serum $\gamma$-globulin, insulin, and egg white lysozyme were purchased from Sigma Co. Ltd.

\section{Synthesis of MPC}

Into a $500 \mathrm{ml}$ three-necked flask equipped with a dropping funnel, thermometer, and drying tube, $20 \mathrm{~g}(0.154 \mathrm{~mol})$ of HEMA, $15.6 \mathrm{~g}$ $(0.154 \mathrm{~mol})$ of TEA and $200 \mathrm{ml}$ of dry THF were placed. After the solution was cooled at $-20^{\circ} \mathrm{C}, 21.9 \mathrm{~g}(0.154 \mathrm{~mol})$ of COP in $100 \mathrm{ml}$ of dry THF were added dropwise to the stirred solution over a period of $1 \mathrm{~h}$. The temperature of the reaction mixture was maintained $-20 \sim-30^{\circ} \mathrm{C}$ for $3 \mathrm{~h}$. Then, the precipitate in the reaction mixture which was triethylammonium chloride was filtered off. The filtrate was evaporated under reduced pressure. To the residue, $50 \mathrm{ml}$ of dry ethyl ether were added to precipitate a small amount of triethylammonium chloride by filtration. By evaporation of filtrate under reduced pressure, colorless liquid, 2-(2-oxo-1,3,2-dioxaphospholoyloxy)ethyl methacrylate (OPEMA) was obtained (yield: $35.5 \mathrm{~g}$ ). The IR and ${ }^{1} \mathrm{H}$ NMR spectra supported the structure of OPEMA. IR $\left(\mathrm{cm}^{-1}\right)$ : $1720(\mathrm{C}=\mathrm{O}), 1640(\mathrm{C}=\mathrm{C}), 1300$, 1240,1160 and $1080\left(-\mathrm{POCH}_{2}-\right) .{ }^{1} \mathrm{H}$ NMR $\left(\mathrm{CDCl}_{3}\right): \delta=2.00 \quad\left(-\mathrm{CH}_{3}, 3 \mathrm{H}\right), 4.00-4.68$ $\left(-\mathrm{CH}_{2}-, 8 \mathrm{H}\right), 5.60(-\mathrm{CH}=, 1 \mathrm{H})$, and 6.20 $(-\mathrm{CH}=, 1 \mathrm{H})$.

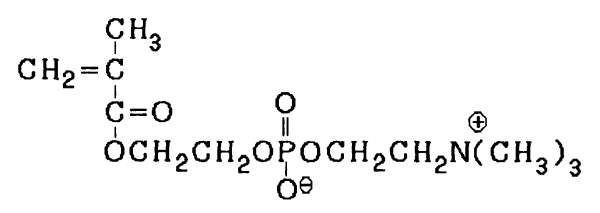

Figure 1. The structure of MPC.

Into a $200 \mathrm{ml}$ glass pressure bottle were placed $5.0 \mathrm{~g}$ of OPEMA and $30 \mathrm{ml}$ of dry acetonitrile. After the bottle was cooled at $-20^{\circ} \mathrm{C}, 2 \mathrm{ml}$ of anhydrous trimethylamine were rapidly added to the solution. The pressure bottle was closed and allowed to warm up to room temperature. After it was heated at $60^{\circ} \mathrm{C}$ for $16 \mathrm{~h}$, the bottle was cooled at $-20^{\circ} \mathrm{C}$, by which procedure a white precipitate, MPC, began to form from the reaction mixture. The MPC was filtered off under argon atmosphere, washed with cold dry acetnitrile and dried under reduced pressure (yield: $3.2 \mathrm{~g}$ ). The structure of MPC is shown in Figure 1. ${ }^{1} \mathrm{H}$ NMR and ${ }^{13} \mathrm{C}$ NMR spectra strongly supported the structure of MPC. ${ }^{1} \mathrm{H}$ NMR $\left(\mathrm{CDCl}_{3}\right): \delta=1.90 \quad\left(-\mathrm{CH}_{3}, 3 \mathrm{H}\right), 3.27-3.36$ $\left(-\mathrm{N}\left(\mathrm{CH}_{3}\right), 9 \mathrm{H}\right), \quad 3.70-3.80\left(-\mathrm{CH}_{2} \mathrm{~N}, 2 \mathrm{H}\right)$, $4.00-4.10\left(\mathrm{POCH}_{2}-, 2 \mathrm{H}\right), 4.21-4.31\left(\mathrm{OCH}_{2}-\right.$ $\left.\mathrm{CH}_{2} \mathrm{OP}, 4 \mathrm{H}\right), 5.60(\mathrm{CH}=, 1 \mathrm{H})$, and 6.10 $(\mathrm{CH}=, 1 \mathrm{H}) \cdot{ }^{13} \mathrm{C} \mathrm{NMR}\left(\mathrm{CDCl}_{3}\right): \delta=18.59$ $\left(-\mathrm{CH}_{3}\right), \quad 54.25\left(\mathrm{~N}\left(\mathrm{CH}_{3}\right)_{3}\right), 59.44\left(\mathrm{CH}_{2} \mathrm{~N}\right)$, $63.34\left(\mathrm{POCH}_{2}-\right), \quad 64.41 \quad\left(-\mathrm{CH}_{2} \mathrm{OP}\right), \quad 66.20$ $\left(\mathrm{OCH}_{2}\right), 126.09\left(=\mathrm{CH}_{2}\right), 136.22(\mathrm{C}=)$, and $167.36\left(\mathrm{CH}_{3}\right)$.

\section{Synthesis and Characterization of Poly (MPC-} co-BMA)

The desired amounts of MPC, BMA and AIBN were dissolved in methanol( $\mathrm{MeOH})$ THF mixture and the solutions taken into polymerization tubes. After oxygen in the tubes was eliminated by bubbling of argon into the solution, the tubes were sealed. Then the tubes were shaken at $60^{\circ} \mathrm{C}$ for $16 \mathrm{~h}$. The contents were cooled to stop the reaction and precipitated by pouring into hexane for copolymers with low MPC composition and into diethyl ether for those with high MPC composition. The 
Phospholipid Polymer Hydrogel

Table I. Compolymerization of MPC and BMA

\begin{tabular}{|c|c|c|c|c|c|c|c|c|c|}
\hline \multirow{2}{*}{ Abb. } & \multicolumn{2}{|c|}{ MPC mole fraction } & \multirow{2}{*}{$\frac{\text { [Monomer] }}{\mathrm{moll}^{-1}}$} & \multirow{2}{*}{$\begin{array}{c}\text { Solvent } \\
\mathrm{MeOH} / \mathrm{THF}\end{array}$} & \multirow{2}{*}{$\frac{\text { Time }}{\mathrm{h}}$} & \multirow{2}{*}{$\frac{\text { Conv. }}{\%}$} & \multirow{2}{*}{$\frac{M_{w}^{\mathrm{b}}}{10^{4}}$} & \multirow{2}{*}{$M_{w} / M_{n}^{\mathrm{b}}$} & \multirow{2}{*}{$\frac{T_{\mathrm{g}}}{{ }^{\circ} \mathrm{C}}$} \\
\hline & in feed & in copolymer ${ }^{\mathbf{a}}$ & & & & & & & \\
\hline MB-1 & 0.05 & 0.039 & 1.43 & $0.13 / 0.87$ & 23 & 35.7 & 2.85 & 1.40 & 24 \\
\hline MB-2 & 0.10 & 0.116 & 1.68 & $0.16 / 0.84$ & 23 & 62.1 & - & - & 27 \\
\hline MB-3 & 0.15 & 0.169 & 0.92 & $0.23 / 0.77$ & 22 & 50.0 & 1.29 & 1.68 & 33 \\
\hline MB-4 & 0.20 & 0.199 & 0.93 & $0.23 / 0.77$ & 24 & 52.4 & - & - & 34 \\
\hline MB-5 & 0.40 & 0.268 & 1.06 & $0.42 / 0.58$ & 24 & 89.8 & - & - & 38 \\
\hline
\end{tabular}

$[\mathrm{AIBN}]=1 \mathrm{~mol} \%$ for monomer.

a Determined by XPS for the membrane.

b Determined by GPC with polystyrene standard.

c Determined by DSC.

precipitate was collected and dried in vacuo. The structure of poly(MPC-co-BMA) was characterized by IR and ${ }^{1} \mathrm{H}$ NMR spectra. IR $\left(\mathrm{cm}^{-1}\right): 1730(\mathrm{C}=\mathrm{O}), 1240,1080\left(-\mathrm{POCH}_{2}-\right)$, $970\left(\mathrm{~N}^{+}\left(\mathrm{CH}_{3}\right)_{3}\right) .{ }^{1} \mathrm{H}$ NMR $\left(\mathrm{CDCl}_{3}\right): \delta=$ $0.85-1.15\left(\alpha-\mathrm{CH}_{3}\right), 1.20-1.42\left(-\mathrm{CH}_{3}\right), 3.23-$ $3.50\left(-\mathrm{N}\left(\mathrm{CH}_{3}\right)_{3}\right), 3.92-4.15\left(-\mathrm{CH}_{2}-\right), 4.16-$ $4.56\left(\mathrm{OCH}_{2} \mathrm{CH}_{2} \mathrm{OP}\right)$.

The poly(MPC-co-BMA) membrane was prepared by the solvent evaporation method to determine MPC composition in the copolymer by X-ray photoelectron spectroscopy (XPS, Shimadzu ESCA-750). XPS analysis was carried out on both sides of the membrane and MPC composition was calculated from the averaged ratio of phosphorus atoms against carbon atoms.

The molecular weight of poly(MPC-coBMA) was determined by GPC in THF with polystyrene standard. The results of the copolymerization of MPC and BMA are summarized in Table I.

By the same polymerization method, poly(AAm-co-BMA) and poly(AMPS-co-BMA) were prepared. The mole fractions of AAm and AMPS were determined from the elemental analysis and they were 0.116 and 0.182 , respectively. The structures of these copolymers were confirmed by IR spectra.

\section{Measurement of the Equilibrium Water Content of Polymer Membrane}

A $5 \mathrm{ml}$ of $\mathrm{MeOH}$-chloroform mixture containing $5 \mathrm{~g}$ of poly(MPC-co-BMA) was cast on a polyethylene plate at room temperature for 1 day, then to removal all trace of the solvent, the membrane was dried in vacuo.

The polymer membrane was immersed in buffer solution with a given $\mathrm{pH}$ value and swollen in a vessel thermostated. The swollen membrane was taken off at regular intervals and excess solution was removed by lightly tamping between filter papers. The membrane was then weighed. The equilibrium water content was calculated by the following equation:

$$
\begin{aligned}
& \begin{array}{l}
\text { Equilibrium water content }= \\
\text { (weight of water in the membrane) }
\end{array} \\
& \text { (weight of membrane swollen) }
\end{aligned}
$$

\section{Permeation Experiment}

The polymer membrane swollen in a buffer solution was interposed between two parts of glass cells. The membrane thickness was $70 \mu \mathrm{m}$. A $60 \mathrm{ml}$ of the buffer solution containing desired amount of solute were put on one side of the cell and a $60 \mathrm{ml}$ of the buffer solution on the other side. Both solutions were slowly stirred. Probes of the buffer solution were taken out after given periods of time and their UV absorptions were measured to determine the 
amount of solute permeated through the polymer membrane.

\section{RESULTS AND DISCUSSION}

\section{Comments on the MPC Synthesis Improved}

Nakabayashi et al., synthesized MPC first by an aminolysis of 2-methacryloyloxyethyl$2^{\prime}$-bromoethyl phosphate (MEBEP). ${ }^{6}$ The MEBEP was synthesized by a condensation reaction between HEMA and 2-bromoethylphosphoryl dichloride, followed by hydolysis with water. In this step, a small amount of water remaining in MEBEP gave adverse effect on the crystallization of MPC since MPC is hygroscopic.

Nakaya et al., reported another synthetic route of MPC. ${ }^{10}$ Methacrylate having cyclic phospholic ester moiety, OPEMA, can be converted to MPC by opening the ester moiety with trimethylamine. There was the advantage that the reaction can be carried out in absolute condition. According to their article, MPC was obtained as a viscous liquid and its melting point was $15^{\circ} \mathrm{C}$. However, it was considered that MPC absorbed water and became a viscous liquid since absolute MPC is a white powder at room temperature. We improved their method in the following points to obtain absolute MPC with good yield. As a solvent for the preparation of OPEMA, THF was used instead of diethyl ether because OPEMA formed is not miscible with diethyl ether. The OPEMA was reacted with triethylamine in acetonitrile to make MPC, the MPC formed was recrystallized from the reaction mixture in situ. By these improvements, MPC was obtained as a white powder easily and ${ }^{1} \mathrm{H}$ and ${ }^{13} \mathrm{C}$ NMR spectra completely corresponded to the structure of MPC.

\section{Hydration of Poly(MPC-co-BMA) Membrane}

The radical copolymerization of MPC with BMA proceeded satisfactorily in an $\mathrm{MeOH}_{-}$ THF mixture. The molecular weight of poly(MPC-co-BMA) obtained was at least $1.2 \times$

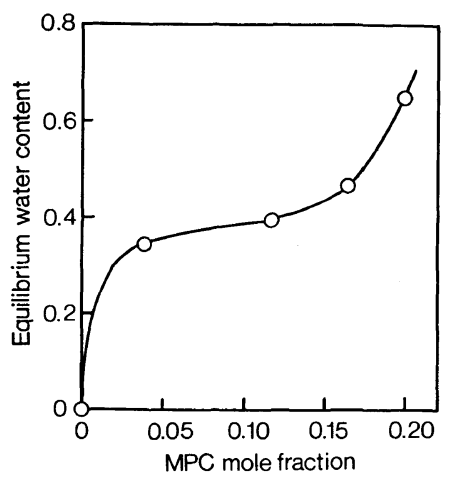

Figure 2. The relation between the MPC composition and the equilibrium water content of poly(MPC-co-BMA) membrane at $30^{\circ} \mathrm{C}, \mathrm{pH} 6.86$.

$10^{4}$. Moreover, the mole fraction of MPC in the copolymer almost corresponded to that in the feed monomers. The glass transition temperature $\left(T_{\mathrm{g}}\right)$ of the copolymers increased with mole fraction of MPC. MB-1, MB-2 and MB-3 were soluble in THF and chloroform, and MB-3, MB-4, and MB-5 were soluble in $\mathrm{MeOH}$ well.

The relation between MPC composition and equilibrium water content of poly(MPC-coBMA) membrane in $\mathrm{pH} 6.86$ at $30^{\circ} \mathrm{C}$ is shown in Figure 2. The equilibrium water content of the poly(BMA) membrane was nearly zero. However, that of the MB-1 membrane which contained only $0.039 \mathrm{MPC}$ in mole fraction was above 0.3 and became a hydrogel. The equilibrium water content increased with MPC composition especially, there was drastic change MPC mole fraction was 0.2 . From these observations, the MPC moiety is effective to increase the water content of the polymer membrane.

Figure 3 shows the temperature dependence of the equilibrium water content of poly(MPCco-BMA) membrane, MB-4, in buffer solution compared with poly(HEMA), poly(AAm-coBMA), and poly(AMPS-co-BMA) membranes. The water content of the MB-4 membrane increased with rise in temperature. The same tendency was found in the copolymer membrane with other MPC compositions. On the 


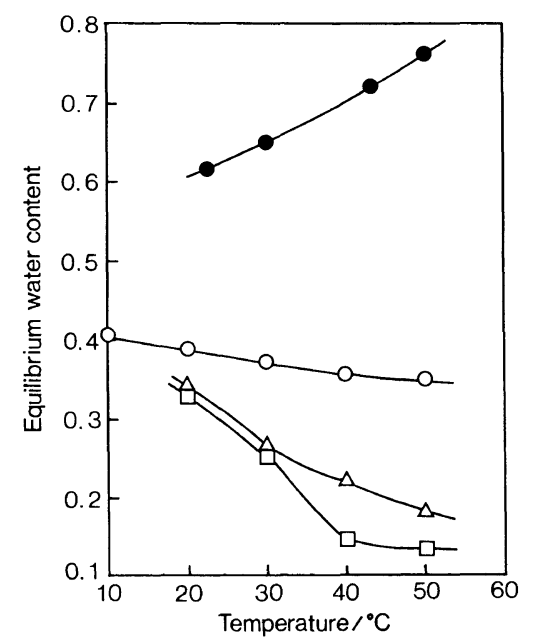

Figure 3. The temperature dependence of the equilibrium water content of amphiphilic hydrogel membrane at $\mathrm{pH}$ 6.86. (O), poly(HEMA); ( $\triangle$ ), poly(AMPS-co-BMA); ( $\square)$, poly(AAm-co-BMA); (О), poly(MPC-co-BMA), MB-4.

other hand, another amphiphilic membrane tested here showed a different tendency against temperature. That is to say, the poly(HEMA) membrane showed a slight decrease of the water content with temperature increase. Moreover, the water content of poly(AAm-coBMA) and poly(AMPS-co-BMA) membranes was strongly sensitive to temperature. There was a drastic decrease of water content of the membrane between $20^{\circ} \mathrm{C}$ and $50^{\circ} \mathrm{C}$.

The effect of temperature on water content noted for the poly(MPC-co-BMA) membrane was very interesting. A comparison of three BMA copolymer membranes showed, the electric charge of hydrophilic moiety to be different. The AAm was nonionic, the AMPS was anionic, and the MPC was zwitter ionic. This difference affected the water structure in the membrane.

It is well known that the water content of a hydrogel membrane having both hydrophilic and hydrophobic groups decreases with rise in temperature. ${ }^{11}$ This can be explained by thermal property of hydrophobic interaction based on the structuring of water in the vicinity of the hydrophobic groups in the membrane. The formation of hydrophobic interaction is

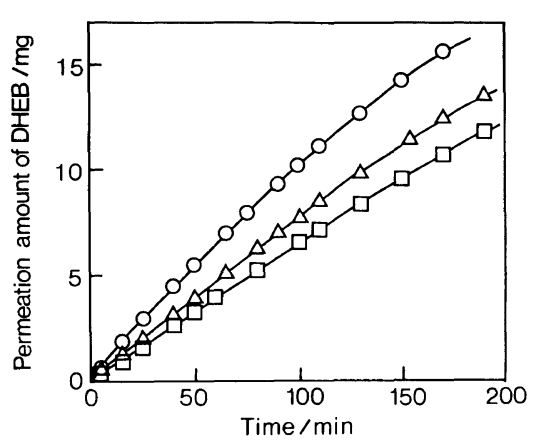

Figure 4. Permeation profile of DHEB through poly(MPC-co-BMA) membrane, MB-3, at various temperature, pH 6.86. Temperature: $(\square) 30^{\circ} \mathrm{C} ;(\triangle), 40^{\circ} \mathrm{C}$; $(O)$, $50^{\circ} \mathrm{C}$. Initial concentration of DHEB in feed side was $2.0 \mathrm{mmoll}^{-1}$.

an endothermic process. ${ }^{12}$ This interaction acts as cross-links in the membrane and reduces the water content of the membrane. ${ }^{13}$ On the other hand, water forms hydrogen bonds with the hydrophilic groups of the polymer and this hydrophilic hydration increases with temperature. The polymer chain should expand entropically with temperature, causing an increase in the capacity for water absorption. In the poly(MPC-co-BMA) membrane case, the later phenomenon was considered to be a dominant factor in the swelling state. Thus, the water content of the poly(MPC-co-BMA) membrane increase with temperature.

The effect of $\mathrm{pH}$ of the medium on the equilibrium water content of the poly(MPCco-BMA) membrane was not considerable. This was supported by the zwitter ionic structure of MPC which was is electrically neutral.

Permeation of Solute through Poly(MPC-coBMA) Membrane

Permeation profiles of 1,4-di(2-hydroxyethoxy)benzene (DHEB) through the poly(MPC-co-BMA) membrane, MB-3, hydrated at various temperatures are shown in Figure 4. The amount of DHEB permeated increased with time linearly at any temperature. When the permeation coefficients were calculated 
from the linear part of the permeation profile, they were $1.73 \times 10^{-6} \mathrm{~cm}^{2} \mathrm{~s}^{-1}$ at $30^{\circ} \mathrm{C}$, $2.10 \times 10^{-6} \mathrm{~cm}^{2} \mathrm{~s}^{-1}$ at $40^{\circ} \mathrm{C}$, and $2.60 \times 10^{-6}$ $\mathrm{cm}^{2} \mathrm{~s}^{-1}$ at $50^{\circ} \mathrm{C}$. The permeation coefficient increased with increase of temperature. This tendency corresponded to the temperature dependence of the equilibrium water content. In the hydrogel membrane system, a solute permeates through the water part in the membrane. ${ }^{14}$ Thus, there was a very close relation between the water content of the membrane and permeation coefficient.

We have already reported that the release rate of DHEB from the poly(MPC-co-BMA) device dispersed with DHEB is regulated by temperature change reversibly, that is, when the temperature raised, the release rate of DHEB increases and as the temperature is lowered, the rate decreases. This is also attributed to the temperature dependence of the water content of the poly(MPC-co-BMA) membrane. ${ }^{15}$

Figure 5 shows the relation between the molecular weight of the solute and permeation coefficient. The permeation coefficient gradually decreased with increase in molecular weight of the solute below $10^{4}$, and drastically decreased above $6 \times 10^{4}$, that is bovine albumin. Bovine $\gamma$-globulin $\left(M_{w}=1.5 \times 10^{5}\right)$ could not permeate the poly(MPC-co-BMA) membrane. Thus, the poly(MPC-co-BMA) membrane can cut off the permeates by their molecular weight. It is one of the important properties to apply the polymer membrane to biomedical field. For example, as for immobilized enzymes for treatment of disease or biosensors, it is necessary that enzymes with large molecular weight do not leak from the polymer membrane and substrates and/or products easily permeate the membrane. Moreover, for preparation of so-call hybrid organs by cell culture technology, immunological problem must be solved by use of polymer membranes which cannot permeate $\gamma$-globulin. We have already found that poly(MPC-coBMA)s have excellent blood compatibility, that

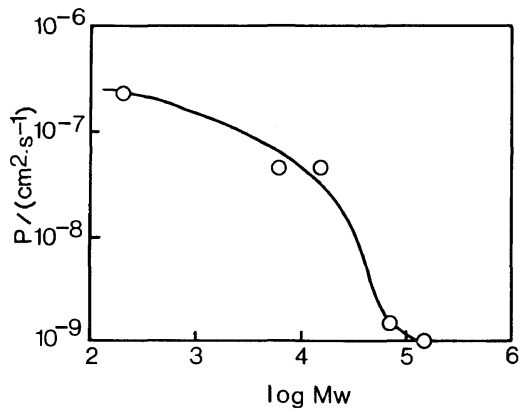

Figure 5. Relation between the molecular weight of solute and permeation coefficient at $30^{\circ} \mathrm{C}, \mathrm{pH} 6.86$. The poly(MPC-co-BMA) membrane is MB-3.

is, prevention of adhesion and activation of platelet and adsorption of serum proteins. ${ }^{16}$ From these observations, poly(MPC-coBMA)s are useful hydrogel materials which can be utilized in biomedical fields.

\section{REFERENCES}

1. D. Chapman, Ed., "Biological Membranes", Academic Press,London, 1968.

2. G. Gregoriadis and A. C. Allison, Ed., "Liposomes in Biological Systems," Wiley, New York, 1980.

3. S. Nojima, J. Sunamoto, and K. Inoue, Ed., "The Liposomes," Nankodo, Tokyo, 1988.

4. S. Nakai, T. Nakaya, and M. Imoto, Makromol. Chem., 178, 2963 (1977).

5. H. H. Hub, B. Hupfer, H. Koch, and H. Ringsdorf, Angew.Chem., 92, 962 (1980).

6. Y. Kadoma, N. Nakabayashi, E. Masuhara, and J. Yamauchi, Koubunshi Ronbunshu, 35, 423 (1978).

7. S. Fukushima, Y. Kadoma, and N. Nakabayashi, Koubunshi Ronbunshu, 40, 785 (1983).

8. J. D. Andrade, Ed., "Hydrogels for Medical and Related Applications," ACS Symp. Ser., 31, 1976.

9. R. S. Edmundson, Chem.Ind. (London), 1828, (1962).

10. T. Umeda, T. Nakaya, and M. Imoto, Makromol. Chem. Rapid Commun., 3, 457 (1982).

11. M. F. Refojo and H. Yasuda, J. Appl. Polym. Sci., 9, 2425 (1965).

12. M. F. Refojo, J. Polym. Sci., A, 5, 3103 (1967).

13. P. H. Corkhill, A. M. Jolly, C. O. Ng, and B. J. Tighe, Polymer, 28, 1758 (1987).

14. H. Yasuda, C. E. Lamaze, and L. D. Ikenberry, Makromol. Chem., 118, 19 (1968).

15. K. Ishihara, T. Ueda, and N. Nakabayashi, Koubunshi Ronbunshu, 46, 591 (1989).

16. K. Ishihara, R. Aragaki, T. Ueda, A. Watanabe, and N. Nakabayashi, Polym. Prepr. Jpn., 38, 566(1989). 